\title{
Water-soluble polyaniline/graphene composites as materials for energy storage applications
}

\author{
A. M. Solonaru*, M. Grigoras \\ 'P. Poni' Institute of Macromolecular Chemistry, Electroactive Polymers Department, 41A Gr. Ghica Voda alley, \\ Iasi-700487, Romania
}

Received 3 August 2016; accepted in revised form 30 September 2016

\begin{abstract}
Three water-dispersable composites have been synthesized by in situ chemical oxidative polymerization of aniline $\mathrm{N}$-propanesulfonic acid (AnS) in reduced graphene oxide (r-GO) dispersion, in an ice bath at $0{ }^{\circ} \mathrm{C}$ and in the absence of any surfactant. The mass ratio between $\mathrm{r}-\mathrm{GO}$ and aniline monomer have been established as $\left(\mathrm{m}_{\mathrm{r}-\mathrm{GO}}: \mathrm{m}_{\mathrm{AnS}}\right)=1: 1,1: 2$ and $1: 5$ while in the composites, the mass ratio between $\mathrm{r}-\mathrm{GO}$ and polyaniline was found: 1:0.3, 1:0.5 and 1:1, respectively. The molecular structure, morphology, and optical properties of the composites were analyzed through Fourier transform infrared (FTIR), Raman and ultraviolet-visible (UV-Vis) spectroscopy, X-ray diffraction (XRD), and scanning electron microscopy (SEM). Electrochemical performances for energy storage were evaluated by cyclic voltammetry and galvanostatic charge/discharge measurements with $1 \mathrm{M} \mathrm{H}_{2} \mathrm{SO}_{4}$ as electrolyte in a three-electrode cell. The composite with the mass ratio $\left(\mathrm{m}_{\mathrm{r}-\mathrm{GO}}: \mathrm{m}_{\mathrm{PAnS}}\right)=$ 1:1 has showed good capacitive behavior with a specific capacitance of $1019 \mathrm{~F} / \mathrm{g}$ at scan rate of $1 \mathrm{mV} / \mathrm{s}$ calculated from integrated area of cyclic voltammogram curve and a retention life of $80 \%$ after 100 cycles. These results indicate that the composites prepared by chemical oxidative polymerization are promising materials for electrode supercapacitors.
\end{abstract}

Keywords: polymer composites, poly(aniline- $N$-propane sulfonic acid), reduced graphene oxide, supercapacitors

\section{Introduction}

Electrochemical capacitors, also called supercapacitors or ultracapacitors, used as energy storage devices have attracted great attention over the past decades due to the fast charge and discharge characteristics, high power density, low cost, a large cycle life and good environment friendliness [1]. Among many promising materials used for supercapacitors, graphene-based composites have been very studied due to their high electron mobility, mechanical strength, exceptional thermal stability and high specific surface area [2,3]. Since its isolation and investigation in 2004 as a single atomic plane of graphite, graphene has attracted huge research interest being one of the most studied and promising materials [4, 5]. Its unique physical, chemical and mechanical properties combined with large surface area, thermal stability, good transmittance and unique optical properties make it suitable for many applications. Graphene has a high surface-to-volume ratio, its theoretical specific surface area is $2675 \mathrm{~m}^{2} / \mathrm{g}$ [6] and capacitance of $550 \mathrm{~F} / \mathrm{g}$ [7] and it has been expected to be a viable candidate for electrochemical energy storage devices $[3,8]$.

Among conducting polymers, polyaniline (PANI) is one of the most studied polymers because of its facile synthesis from a cheap monomer, environmental stability, multiple and reversible electrochemical redox states and doping using a variety of $p$ - or $n$-dopants or using protonic inorganic or organic acids as well as its potential in commercial application [9-11]. However, the low solubility of the doped polymer in most organic solvents, the poor mechanical properties and low processability and poor cycling stability are

*Corresponding author, e-mail: solonaru.anamaria@icmpp.ro (C) BME-PT 
major drawbacks for practical use and many attempts have tried to surpass these difficulties. Polyanilines containing sulfonate groups are of great interest due to their interesting electroactive properties, good processability and practical applications. Unlike PANI, sulfonated polyanilines are water soluble and self-doped conducting polymers and have $\mathrm{pH}$-independent conductivity from 0 to 14 [12].

Combining the unique properties of graphene and polyaniline, graphene/polyaniline composites are a new class of performing materials that have attracted much attention of researchers in the last years due to the synergistic effects on their thermal, electronic and mechanical properties [13-15]. They have been developed and investigated for use mainly as high-performance supercapacitor electrode materials [16], microwave shielding [17], corrosion protection [18] or counter-electrode for dye-sensitized solar cells [19]. The performances of graphene/PANI composites are strongly dependent on the interfacial interactions between partners providing a blending to molecular level, without segregation during synthesis and operation. The most used method to obtain graphene/ PANI nanocomposites is based on in situ chemical polymerization of aniline monomers in presence of graphene derivatives dispersion [20-23]. The mixing at molecular level of insoluble and rigid-rod conjugated polymers (i.e., polyaniline) with platelets of graphene is a difficult task and not favored from thermodynamic point of view. A problem that appears in the case of graphene is the strong $\pi$ - $\pi$ interaction between platelets, leading to insolubility in any solvent and irreversible agglomeration during nanocomposites synthesis step or operation. Even after the lasting ultrasonic treatment graphene doesn't form homogeneous composites. Some approaches have been applied to suppress graphene platelets agglomeration and formation of stable and well waterdispersable graphene/PANI compositions:

(i) use of aniline surfactants (anilinium salts of dodecylbenzenesulfonate or dodecylsulfate) [24], but removing of surfactant from final composites is a necessary step.

(ii) use of functionalized graphene as dopant of PANI. Sulfonated graphene has the advantage to be water-soluble and play a dual role, as template host for aniline polymerization and also as external dopant for polyaniline. Well water-dispersable graphene/PANI composites were obtained using sulfonated graphene [25-30]. (iii) covalently grafted PANI onto graphene by polymerization of aniline in presence of graphene containing amine groups. Another way to increase the miscibility and to obtain more uniform dispersion is to use water-soluble poly (styrene sulfonic acid)-graft-polyaniline [31,32] or polyaniline grafted onto graphene [33-35].

In this research we report the synthesis, characterization and electrochemical performances of new water-dispersable nanocomposites based on reduced graphene oxide (r-GO) and water-soluble poly(aniline- $N$-propanesulfonic) acid (PAnS). The composites were obtained by in situ chemical polymerization of aniline- $N$-propanesulfonic acid in a dispersion of $\mathrm{r}-\mathrm{GO}$, using ammonium peroxydisulfate as oxidant. The synthesis was carried out in the absence of any surfactant, aniline propane sulfonic acid playing both the role of surfactant and monomer for synthesis of polyaniline, while resulting polymer is polyionic surfactant for graphene dispersion in water. The synthesis method is simple and inexpensive because it does not require surfactants and inorganic or organic acids as the dopant, opening a new way to prepare hybrid materials and has a great potential for the applications especially for electrochemical supercapacitors. A few numbers of studies of the synthesis of sulfonated polyaniline/r-GO have been reported [36, 37].

\section{Experimental}

\subsection{Reagents}

Graphite powder and aniline (both from Reactivul Bucuresti), potassium permanganate, hydrazine hydrate $(80 \%)$, ammonium peroxydisulfate, propane sultone (all from Aldrich) were used as received. Graphene oxide (GO) was prepared from graphite powder by the modified Hummers method using concentrated sulfuric acid and potassium permanganate as oxidant [38]. The synthesis of aniline- $N$-propanesulfonic acid (AnS) was reported in our previous paper [39].

Reduced graphene nanosheets (r-GO) were synthesized by reducing graphene oxide with hydrazine hydrate [21]. In a typical synthesis process, to a $100 \mathrm{~mL}$ ultrasonated aqueous suspension containing $1 \mathrm{~g} \mathrm{GO}$ maintained at $2-5^{\circ} \mathrm{C} 1 \mathrm{~mL}$ hydrazine monohydrate was dropwise added for one hour and the suspension was stirred and maintained at $95^{\circ} \mathrm{C}$ for $3 \mathrm{~h}$. Once the reaction is completed, $\mathrm{r}-\mathrm{GO}$ was collected by filtration as a black powder, washed several times with 
deionized water to remove excess hydrazine, and dried at $60^{\circ} \mathrm{C}$.

\section{Synthesis of dispersible r-GO/PAnS composites}

The homogeneous r-GO/PAnS composites with three different mass ratios were prepared by in situ oxidative polymerization of $\mathrm{AnS}$ in a dispersion of r-GO in aqueous acidic solution. In a typical synthesis of $\mathrm{r}-\mathrm{GO} / \mathrm{PAnS}, 100 \mathrm{mg} \mathrm{r-GO}$ were dispersed in $45 \mathrm{~mL}$ $1 \mathrm{M} \mathrm{HCl}$ solution and ultrasonicated for $2 \mathrm{~h}$ to obtain a homogeneous dispersion. After which a quantity of AnS (calculated for 1:1, 1:2 and 1:5 weight ratio between $\mathrm{r}-\mathrm{GO} / \mathrm{AnS}$, and the resulted composites were noted as r-GO/PAnS-1, r-GO/PAnS-2, and r-GO/ PAnS-3) was added and the whole suspension was sonicated for further $2 \mathrm{~h}$ and then introduced in a water bath and cooled at $0^{\circ} \mathrm{C}$. A freshly prepared solution of the oxidant (ammonium peroxydisulfate) in $5 \mathrm{~mL}$ of $1 \mathrm{M} \mathrm{HCl}$ (molar ratio between aniline monomer and oxidant $=1 / 1.5$ ) was gradually added drop by drop into the stirred suspension at a reaction temperature of $0-5^{\circ} \mathrm{C}$ and then maintained at this temperature for $4 \mathrm{~h}$. Polymerization of aniline monomer has started after about $1 \mathrm{~min}$ when a green color starts to develop in suspension, in time the suspension turned from dark-grey to green. The r-GO/PAnS nanocomposites were recovered by filtration and rinsed several times with cold distilled water and methanol. The powder thus obtained was vacuum dried at $60^{\circ} \mathrm{C}$ for $24 \mathrm{~h}$. Yields: $0.1335 \mathrm{~g}$ (r-GO/ PAnS-1), $0.1571 \mathrm{~g}$ (r-GO/PAnS-2), $0.2124 \mathrm{~g}$ (r-GO/ PAnS-3).

\subsection{Instruments}

FT-IR spectra were recorded on $\mathrm{KBr}$ pellets using a DIGILAB-FTS 2000 spectrometer. The UV-Vis spectra of the composites were measured using an UVVis SPECORD 200 Analytik Jena spectrometer (Analytik Jena AG, Jena, Germany). A micro-Raman system (Renishaw, inVia Reflex) equipped with a $633 \mathrm{~nm}$ He-Ne laser $(17 \mathrm{~mW})$ and an optical microscope (Leica DM $2500 \mathrm{M}$ ) was used. The laser beam was focused through a $50 \times$ objective lens (Leica, N Plan EPI) with a numerical aperture of 0.75 . Scattered light was collected in a backscattered geometry. The range of vibrational frequencies was from 100 to $3200 \mathrm{~cm}^{-1}$. Three scans were accumulated for each spectrum, and the laser exposure for each scan was $15 \mathrm{~s}$ in order to achieve an adequate signal-to-noise ratio. The Raman measurements were performed at room temperature and atmospheric pressure. All samples were investigated in powder form and no further sample preparation was applied. XRD measurements were performed with a Bruker AD8 ADVANCE apparatus. The $\mathrm{X}$-ray beam was $\mathrm{CuK} \alpha_{1}(1.5406 \AA)$ radiation operating from a sealed tube operated at $40.0 \mathrm{kV}$ and $30 \mathrm{~mA}$. Data from 3 to $60^{\circ}(2 \theta)$ were obtained using Bragg-Brentano geometry at a scan rate $1.0^{\circ} / \mathrm{min}$. The morphology of composites was studied by scanning electron microscopy (SEM) using a Scanning Electron Microscopy Quanta 200 apparatus. A three-electrode cell system was used to evaluate electrochemical performance using cyclic voltammetry $(\mathrm{CV})$ and galvanostatic charge-discharge using a Bioanalytical System, Potentiostat-Galvanostat (BASi 100B/W, SUA, Indiana, West Lafayette). For electrochemical studies $10.0 \mathrm{mg}$ sample was dispersed in $15 \mathrm{~mL}$ water by sonication and the dispersion was cast onto a glassy carbon electrode which was used as working electrode. The electrode was dried before electrochemical measurements and mass of the material was 4-7 mg. A platinum wire and a saturated $\mathrm{Ag} / \mathrm{AgCl}$ electrode were used as the counter and reference electrode, respectively. CV curves were measured between $-0.2 \ldots+0.8 \mathrm{~V} v s \mathrm{Ag} /$ $\mathrm{AgCl}$ at different scan rates using an aqueous solution of $1 \mathrm{M} \mathrm{H}_{2} \mathrm{SO}_{4}$ as electrolyte. Galvanostatic charge-discharge tests were performed at a current of $1 \mathrm{~mA}$.

\section{Results and discussion}

\subsection{Composite synthesis}

The composites based on r-GO and PAnS were prepared by in situ chemical polymerization of aniline monomer onto surface of $\mathrm{r}-\mathrm{GO}$ dispersed in aqueous solution. The polymerization was carried out at $0{ }^{\circ} \mathrm{C}$ for $4 \mathrm{~h}$ using ammonium peroxydisulfate as oxidant and three mass ratios between $\mathrm{r}-\mathrm{GO}$ and $\mathrm{AnS}$ were calculated for starting dispersions: $\mathrm{m}_{\mathrm{r}-\mathrm{GO}} / \mathrm{m}_{\mathrm{AnS}}=1: 1$, 1:2, and 1:5, to obtain three composites: r-GO/PAnS-1, r-GO/PAnS-2, and r-GO/PAnS-3, respectively (Figure 1). The content of PAnS in composites was determined gravimetrically, as difference between total quantity and r-GO $(0.1 \mathrm{~g})$. The mass ratios between $\mathrm{r}-\mathrm{GO}$ and PAnS in composites were determined as $\sim 1: 0.3$ (r-GO/PAnS-1), 1:0.5 (r-GO/PAnS-2) and 1:1 (r-GO/PAnS-3).

AnS and corresponding polymer contain negatively charged $\mathrm{SO}_{3}{ }^{-}$groups and therefore it can play an important role in that it provides stabilization of $\mathrm{r}-\mathrm{GO}$ 


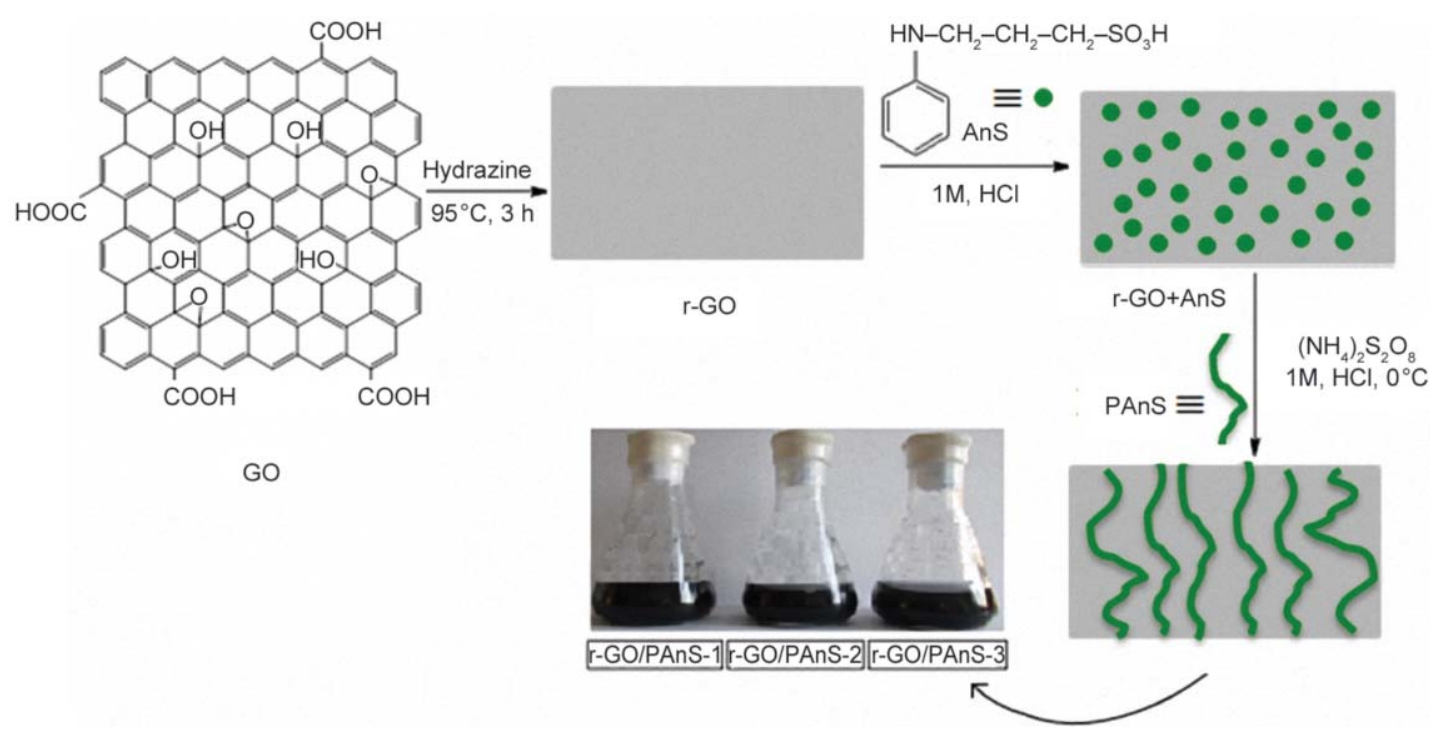

Figure 1. Schematic illustration of preparation of r-GO/PAnS composites

dispersions, allowing production of homogeneously dispersion of r-GO in water by sonication and stirring. The dispersion $\mathrm{r}-\mathrm{GO} / \mathrm{AnS}$ in water was stable in absence of stirring for 1-2 hours while the dispersion between $\mathrm{r}-\mathrm{GO}$ and aniline obtained in the same conditions has separated after $30 \mathrm{~min}$. AnS is firstly adsorbed on the surface and between the r-GO sheets by $\pi-\pi$ and electrostatic interactions and hydrogen bonding between carboxyl groups of r-GO and amine groups from monomer while $\mathrm{SO}_{3} \mathrm{H}$ groups maintain $\mathrm{r}-\mathrm{GO}$ in dispersion. Finally, by polymerization r-GO sheets are covered by an adherent polyaniline film. The final $\mathrm{r}-\mathrm{GO} / \mathrm{PAnS}$ dispersion is more stable than initial $\mathrm{r}-\mathrm{GO} / \mathrm{AnS}$ dispersion due to the cooperative effect of $-\mathrm{SO}_{3}$ groups from polyionic conducting polymer. Though pure PAnS is soluble in water resulting green-colored solutions of self-doped polyaniline, the r-GO/PAnS composites were separated from aqueous dispersion by filtration and washed with cold water and methanol. The PAnS strongly adhere to r-GO surface and cannot be removed by washing with water. After drying a more compact structure with more intensive interactions is formed. The low yields obtained in synthesis of composites can be explained because they are reported only for the quantity of PAnS bonded to r-GO surface, while the non-bonded PAnS is removed as polymer dissolved in water. Usually, polymerization of AnS carried out in the same experimental conditions and separated by precipitation in acetone, was performed with good yields [39].

\subsection{FTIR analysis}

FT-IR spectra of the individual compounds and their composites are presented in Figure 2. GO shows the absorption at $1733 \mathrm{~cm}^{-1}$ assigned to stretching vibrations of $-\mathrm{C}=\mathrm{O}$ from carboxyl groups. Other absorption peaks associated with carboxyl (CO), epoxy (OCO) and alcoxi (CO) functions can be found at 1401,1220 and $1069 \mathrm{~cm}^{-1}$, respectively. The broad and intense absorption centered at $3442 \mathrm{~cm}^{-1}$ is assigned to the $-\mathrm{OH}$ stretching vibration in $-\mathrm{COOH}$ and intercalated water. After reducing $\mathrm{GO}$ with hydrazine, IR spectrum of r-GO shows fewer bands than GO, remembering IR spectrum of graphite. However, some absorption peaks from GO $(1725,1564$ and $1179 \mathrm{~cm}^{-1}$ which are attributed to the characteristics of $\mathrm{C}=\mathrm{O}, \mathrm{C}=\mathrm{C}$ and $\mathrm{C}-\mathrm{O}$ in $\mathrm{C}-\mathrm{O}-\mathrm{H}$ groups) are preserved because the reduction is not complete, and at least the carboxyl groups on the edges of the GO remain unmodified.

The FTIR spectrum of PAnS has evidenced characteristic peaks for $\mathrm{HCl}$ - and/or self-doped polyaniline form, (emeraldine salt form). The peak at $1570 \mathrm{~cm}^{-1}$ corresponds to the $\mathrm{C}=\mathrm{C}$ ring stretching vibration of the quinoid structures while the peak at $1500 \mathrm{~cm}^{-1}$ corresponds to $\mathrm{C}=\mathrm{C}$ ring stretching vibration of the benzenoid structure. The characteristic band assigned to the symmetric and asymmetric sulfonic groups stretching vibration can be observed at 1140 and $1040 \mathrm{~cm}^{-1}$, respectively. The broad absorption bands at $2800-3500 \mathrm{~cm}^{-1}$ are due to the $\mathrm{C}-\mathrm{H}$ aliphatic from propane sultone substituent and $\mathrm{N}-\mathrm{H}$ stretching 

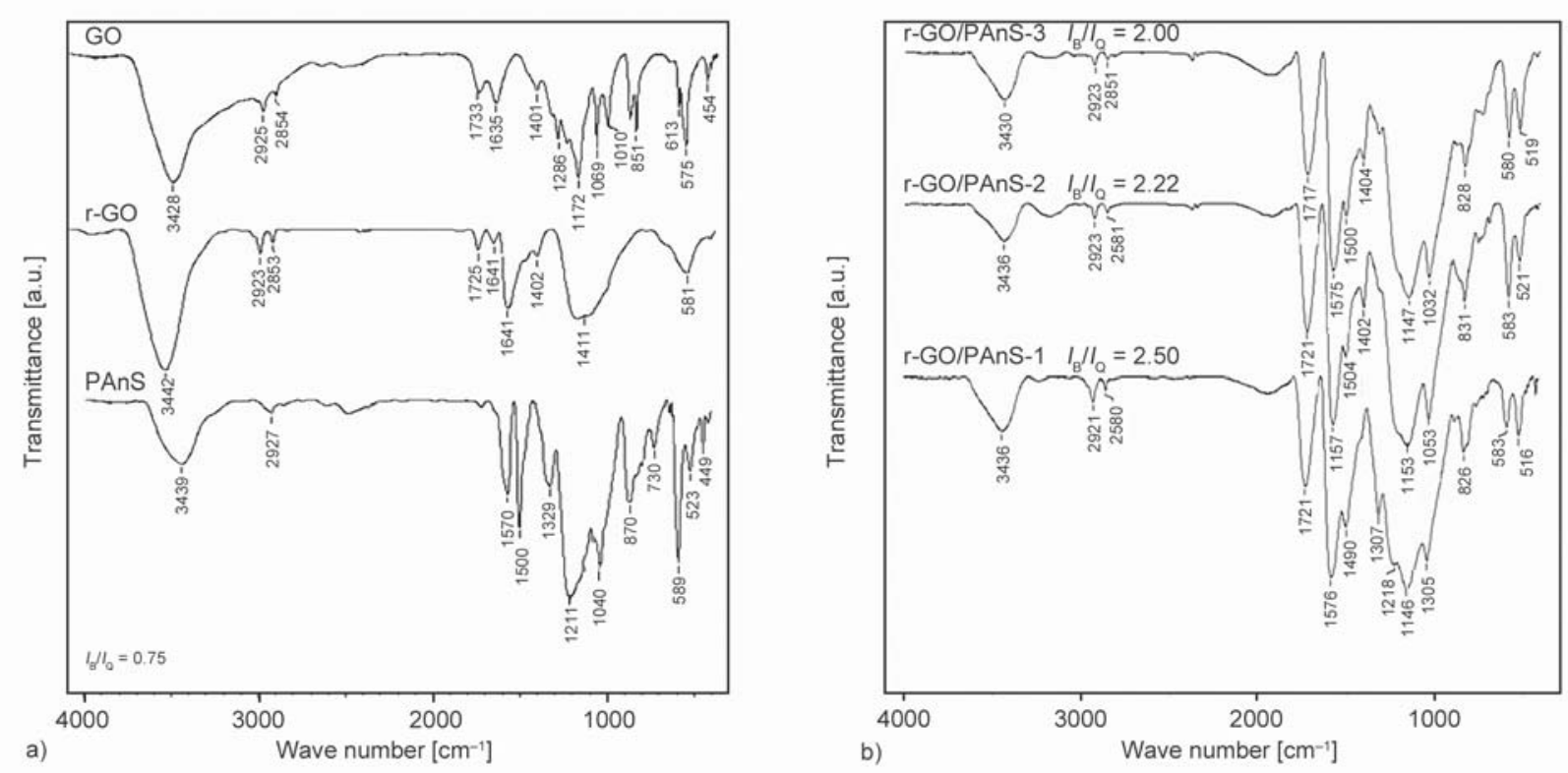

Figure 2. FT-IR spectra (KBr pellet) of a) graphene oxide (GO), reduced graphene oxide (r-GO), and polyaniline derivative (PAnS); b) composites, r-GO/PAnS-3, r-GO/PAnS-2, r-GO/PAnS-1

vibration mode. The $\mathrm{O}-\mathrm{H}$ moiety of the free $-\mathrm{SO}_{3} \mathrm{H}$ group also absorbs in this region. The peak at $1329 \mathrm{~cm}^{-1}$ is related to $\mathrm{C}-\mathrm{N}$ stretching modes in the benzenoid and quinoid imine units [39].

The FTIR spectra of r-GO/PAnS composites are given in Figure 2b. All characteristic peaks of individual $\mathrm{r}-\mathrm{GO}$ and PAnS coexist in the spectra of composites suggesting the presence of both components. The presence of quinoid and benzenoid ring vibrations $(\mathrm{C}=\mathrm{C})$ stretching deformations was found in the spectrum at 1574 and $1500 \mathrm{~cm}^{-1}$ for $\mathrm{r}-\mathrm{GO} / \mathrm{PAnS}-1$, 1577 and $1504 \mathrm{~cm}^{-1}$ for r-GO/PAnS-2 and 1576 and $1490 \mathrm{~cm}^{-1}$ for $\mathrm{r}-\mathrm{GO} / \mathrm{PAnS}-3$. There are also found the characteristics bands assigned to the symmetric and asymmetric sulfonic groups stretching vibration at 1147 and $1032 \mathrm{~cm}^{-1}$ for $\mathrm{r}-\mathrm{GO} / \mathrm{PAnS}-1,1153$ and $1053 \mathrm{~cm}^{-1} \mathrm{r}-\mathrm{GO} / \mathrm{PAnS}-2$ and 1146 and $1035 \mathrm{~cm}^{-1}$ for $\mathrm{r}-\mathrm{GO} / \mathrm{PAnS}-3$. The presence of these bands indicates the formations of PAnS on the r-GO surface. The peak that appeared at $1721 \mathrm{~cm}^{-1}$ is assigned to $\mathrm{C}=\mathrm{O}$ stretching vibration of the carboxylic $-\mathrm{COOH}$ group from $\mathrm{r}-\mathrm{GO}$. The benzenoid band was more intense in the composites, the ratio of the absorption intensity of the benzenoids to quinoids $\mathrm{C}=\mathrm{C}$ vibrations varies between 2.00-2.50 for composites while for PAnS is 0.75 , due to the contribution of $\mathrm{C}=\mathrm{C}$ benzenoid vibration from $\mathrm{r}-\mathrm{GO}$. The IR results demonstrate the presence of both components in the composites and the successful combinations of these was attributed to $\pi-\pi$ interaction and hydrogen bonding.

\subsection{Raman spectroscopy}

The Raman spectrum of GO has displayed two strong peaks at 1341 and $1602 \mathrm{~cm}^{-1}$, corresponding to the $\mathrm{D}$ (is related to the presence of edges and defects in the $\mathrm{sp}^{2}$ lattice, being absent for pure graphene monolayers) [40] and $\mathrm{G}$ bands (is related to $\mathrm{sp}^{2}$ carbon network) [41], respectively and the intensity ratio $I_{\mathrm{D}} / I_{\mathrm{G}}$ is approximately 0.97 (Figure 3)). A broad absorption above $2660 \mathrm{~cm}^{-1}$ is observed and is assigned to the $2 \mathrm{D}$ band and its presence suggests the existence of multilayers besides monolayers of graphene [42]. After reduction, the $\mathrm{D}$ and $\mathrm{G}$ bands of $\mathrm{r}-\mathrm{GO}$ are shifted to lower wavenumber (1334 and $1592 \mathrm{~cm}^{-1}$, respectively). The $\mathrm{D} / \mathrm{G}$ intensity ratio for $\mathrm{r}-\mathrm{GO}$ is 1.15 , higher than $\mathrm{GO}$ and this is assigned to the formation of an increased number (but smaller in size) of $\mathrm{sp}^{2}$ domains than GO [43]. The spectrum of PAnS shows the main bands situated at 577, 727, 1168, 1315, 1471,1602 and $1648 \mathrm{~cm}^{-1}$ assigned to out of plane $\mathrm{C}-\mathrm{N}-\mathrm{C}$ torsion, imine deformation, $\mathrm{C}-\mathrm{H}$ bending of quinoid ring in plane, $-\mathrm{C}-\mathrm{N}+$. stretching vibration of bipolaron structure, $-\mathrm{C}=\mathrm{N}$ stretching vibration of quinoid ring, $-\mathrm{C}-\mathrm{C}$ stretching of benzenoid, and $\mathrm{N}-\mathrm{H}$ bending of bipolaronic structure, respectively. It is observed that there are two prominent peaks in Raman spectrum of composites corresponding to the $\mathrm{D}$ band and $\mathrm{G}$ band of the r-GO. Also, the peaks at 577 and $1168 \mathrm{~cm}^{-1}$ assigned to PAnS are observed while other peaks from PAnS cannot be evidenced because are too weak or are overlapped. Comparing 

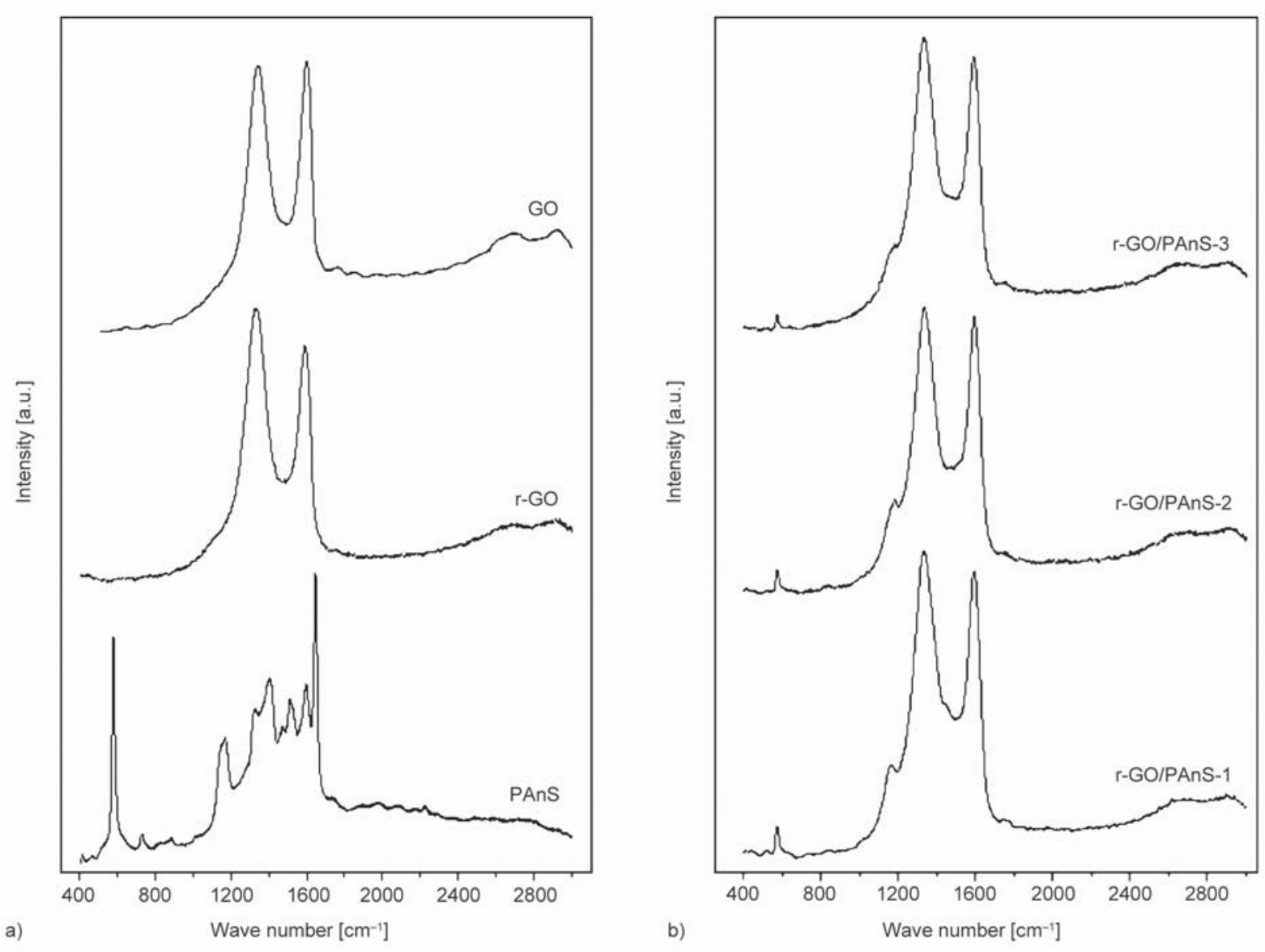

Figure 3. Raman spectra of a) graphene oxide (GO), reduced graphene oxide (r-GO), and polyaniline derivative (PAnS); b) r-GO/PAnS-3, r-GO/PAnS-2, r-GO/PAnS-1

the ratios intensities of the $\mathrm{D}$ and $\mathrm{G}$ bands it can see that the ID/IG ratio decreases from 1.15 for $\mathrm{r}-\mathrm{GO}$ to 1.06 for $\mathrm{r}-\mathrm{GO} / \mathrm{PAnS}-1,1.04$ for $\mathrm{r}-\mathrm{GO} / \mathrm{PAnS}-2$ and 1.01 for $\mathrm{r}-\mathrm{GO} / \mathrm{PAnS}-3$, respectively due to the overlapping and contribution of the peaks $(1315,1471,1602$ and $1648 \mathrm{~cm}^{-1}$ ) from PAnS to broad D and G bands.

\subsection{UV spectra}

The UV-Vis spectra of PAnS and composites are shown in Figure 4. Absorption spectrum of selfdoped PAnS in aqueous solution presents bands at 320,430 and above $1000 \mathrm{~nm}$, corresponding to the $\pi-\pi^{*}$ transition in benzene rings, and for optical absorptions of the localized and delocalized polarons, respectively [39]. For composite r-GO/PAnS-1 two peaks are observed at 243 and $320 \mathrm{~nm}$ (shoulder). The first absorption peak is assigned to the electronic conjugation within the reduced graphene oxide and the absorption shoulder is associated with $\pi-\pi^{*}$ transition in PAnS. With increasing content of PAnS in composites the UV absorption characteristic for it can be more clearly observed. The UV-Vis spectra of the composites show the characteristic peaks of

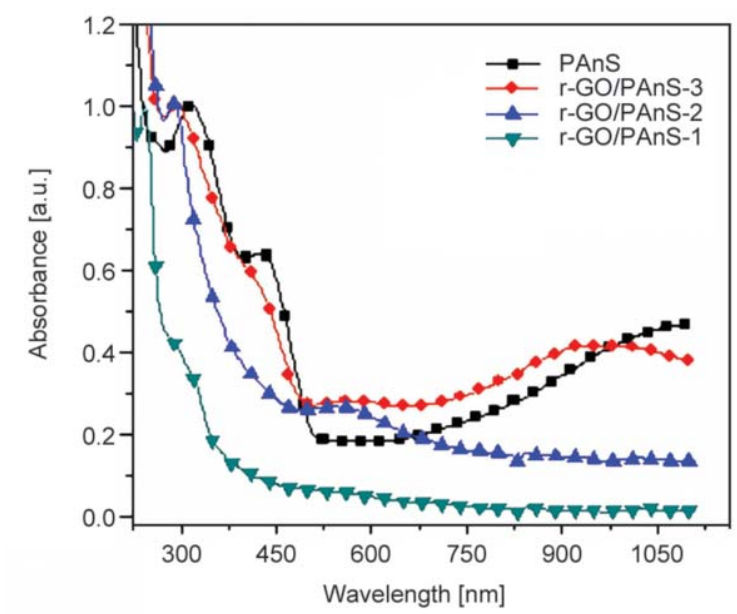

Figure 4. Absorption spectra (H2O) of PAnS, r-GO/PAnS-1, r-GO/PAnS-2 and r-GO/PAnS-3

PAnS and r-GO and confirm the formation of the composites.

\subsection{X-ray studies}

The structure of the composites was also investigated by X-ray diffraction measurement. The X-ray diffraction patterns of graphite, GO, r-GO, and composites are presented in Figure 5. 

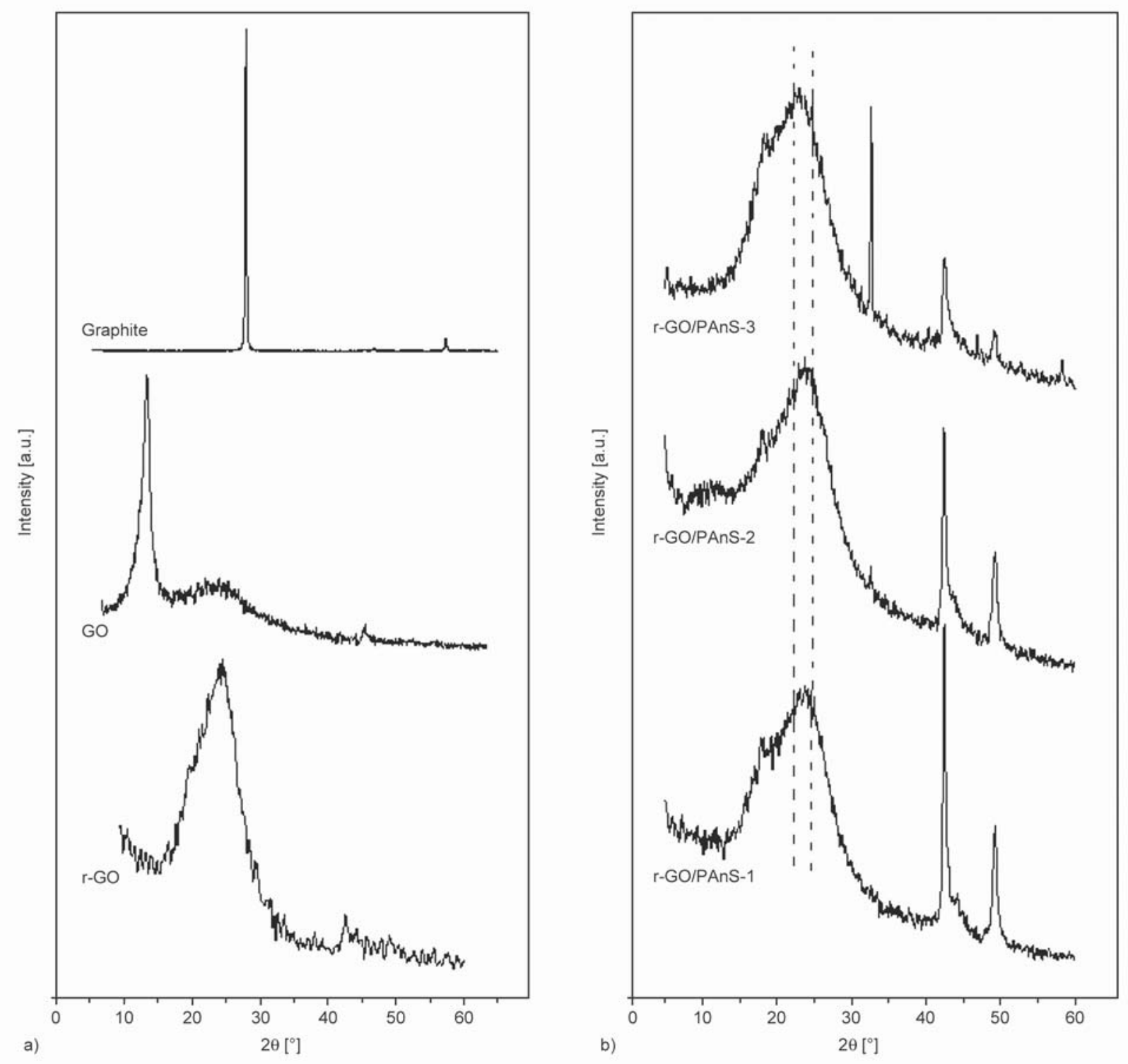

Figure 5. XRD patterns of: a) graphite, GO, r-GO; b) r-GO/PAnS-3, r-GO/PAnS-2, r-GO/PAnS-1

GO shows a lamellar morphology where $-\mathrm{OH}$ and epoxide functional groups destroy planar and hexagonal structure of carbon and decrease van der Waals forces between layers and thus increasing distance between them. Due to the functional groups, GO can be dispersed in hydrophilic solvents. In the graphite, the distance between layers is $\sim 0.33 \mathrm{~nm}$ and is increased to $0.78 \mathrm{~nm}$ in GO. This is clearly evidenced by X-ray spectra, where the maximum observed at $2 \theta=26.31^{\circ}$ in graphite is shifted at a $2 \theta=11.33^{\circ}$ characteristic for GO. Also a wider maximum of low intensity appears at $2 \theta=17.0^{\circ}$ indicating a less homogeneous structure of GO. After reducing of GO to the r-GO, the peak from $2 \theta=11.33^{\circ}$ disappears and another peak appears, much wider than in the graphite at $2 \theta=24.21^{\circ}$ suggesting a less ordered structure. By reducing, the $\mathrm{OH}$ and epoxy groups situated in basal plane disappear but edges $\mathrm{COOH}$ groups remain and contribute to a greater distance between layers of $0.33 \mathrm{~nm}$.

The X-ray diffraction pattern of PAnS shows crystalline peaks indicating a high degree of crystalinity due to the periodicity parallel to the polymer chain [39]. The development of the highly ordered structures for self-doped poly(aniline-N alkanesulfonate)s was evidenced by Kim et al. [44] and can be explained by ionic interactions between propane sulfonate anions and the imine nitrogens from the main chain resulting in the layering of the polyaniline chains. The aqueous polymer solutions formed also highly liquid crystalline phases with high orientational and positional order associated with ionic interactions between alkylsulfonates groups and polyaniline main chain. 
In the XRD patterns of composites appears broad peak at $\sim 24^{\circ}$ indicating that $\mathrm{r}-\mathrm{GO}$ is present in the structure of these materials. On the other hand the composites exhibit sharps peaks $\left(32,42\right.$ and $\left.49^{\circ}\right)$ corresponding to PAnS crystalline structure, more clearly evidenced for $\mathrm{r}-\mathrm{GO} / \mathrm{PAnS}-3$.

The maximum $\left(2 \theta=24.21^{\circ}\right)$ corresponding to $\mathrm{r}-\mathrm{GO}$ is shifted in composites to lower values and a such expansion of layer distance can be explained by the adsorption and intercalation of the PAnS on the surface and between the r-GO sheets.

\subsection{Morphology of composites}

The morphology of r-GO, PAnS and composites, deposited as films, was investigated by SEM. As seen from images in Figure 6 the r-GO has folded and wrinkled sheets randomly aggregated to form disordered solids. The micrograph of PAnS shows a plate like feature with 100-200 $\mathrm{m} \mu$ sizes resulted from aggregation of small and irregular particles of different shapes and dimensions. Some representative SEM images of composites compared to r-GO and PAnS show an evidently aggregated structure composed of many PAnS nanofibers, nanoplates and nanoparticles aggregated onto the r-GO surfaces. The visual observation suggests that by increasing the amount of

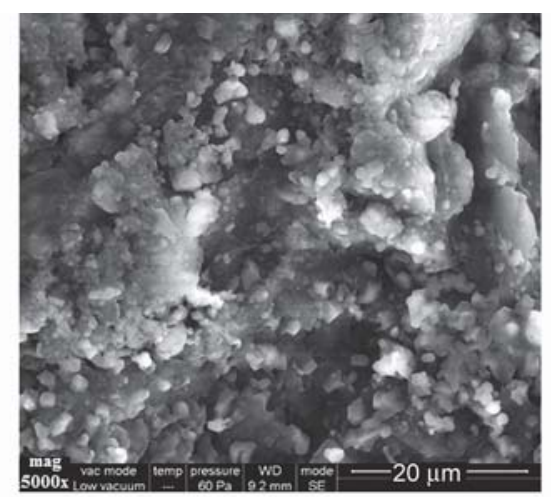

a)

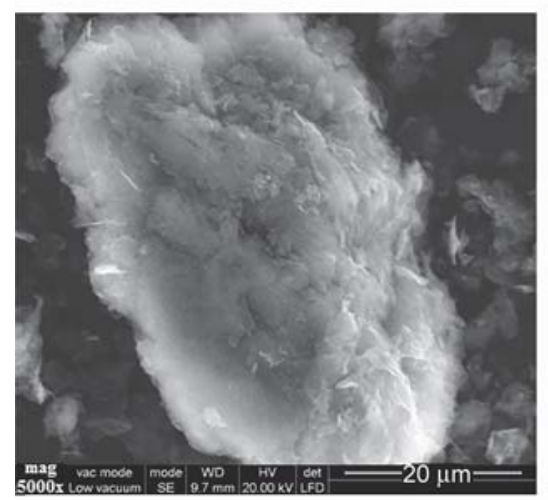

c)

d)
AnS, more PAnS were coated on the surface of $r$ GO. So, the absorption and intercalation of PAnS on the surface of graphene should be responsible for the composites morphology [30].

\subsection{Electrochemical performances}

Electrochemical studies were carried out using composites as the electrode material and cyclic voltammetry $(\mathrm{CV})$ and galvanostatic charge-discharge techniques in a three-electrode cell. Usually, the CV curve of $\mathrm{r}-\mathrm{GO}$ shows a typical rectangular shape without redox peaks, and the energy is stored by electrical double-layer (EDL) between r-GO and electrolyte (non-faradaic mechanism) [1, 2]. Typical CV curves of the composites in $1 \mathrm{M} \mathrm{H}_{2} \mathrm{SO}_{4}$ measured within the potential window from -0.2 to $+0.8 \mathrm{~V}$ versus $\mathrm{Ag} / \mathrm{AgCl}$ electrode at various scan rates are given in Figure 7. The CV curves of composites show two pairs of redox peaks that are assigned to the transition of polyaniline chain from leucoemeraldine salt to emeraldine salt, and then between emeraldine salt and pernigraniline salt. Therefore, the capacitance of polyaniline materials is mainly based on redox reactions (faradaic mechanism) and also EDL mechanism [34]. The shape of the CVs for these composites remains unchanged from 1 to $200 \mathrm{mV} / \mathrm{s}$ indicating

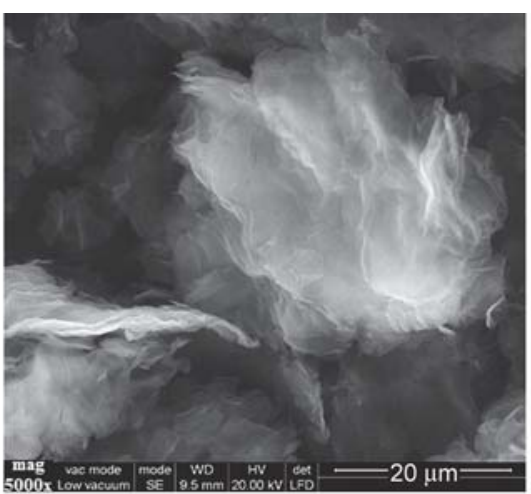

b)
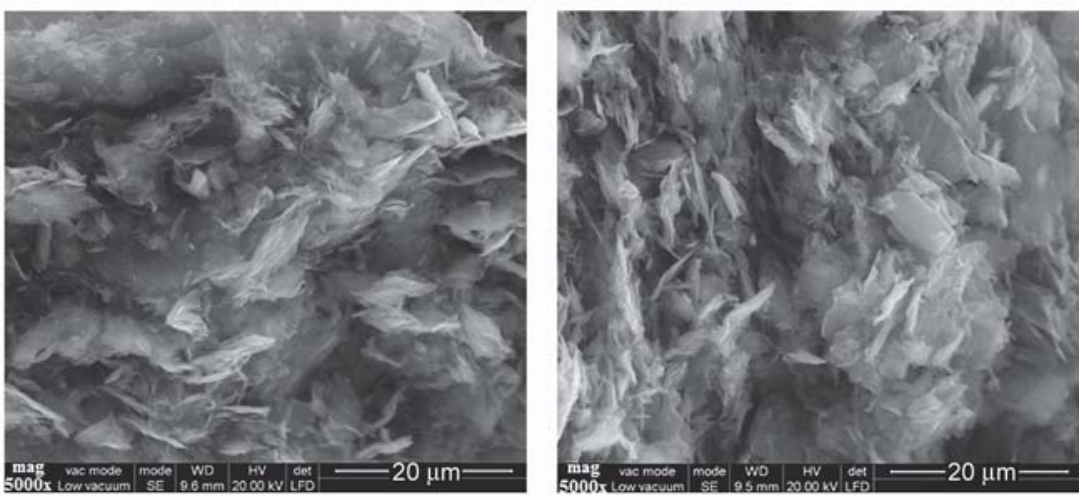

e)

Figure 6. SEM images of a) PAnS, b) r-GO, c) r-GO/PAnS-1, d) r-GO/PAnS-2, e) r-GO/PAnS-3 

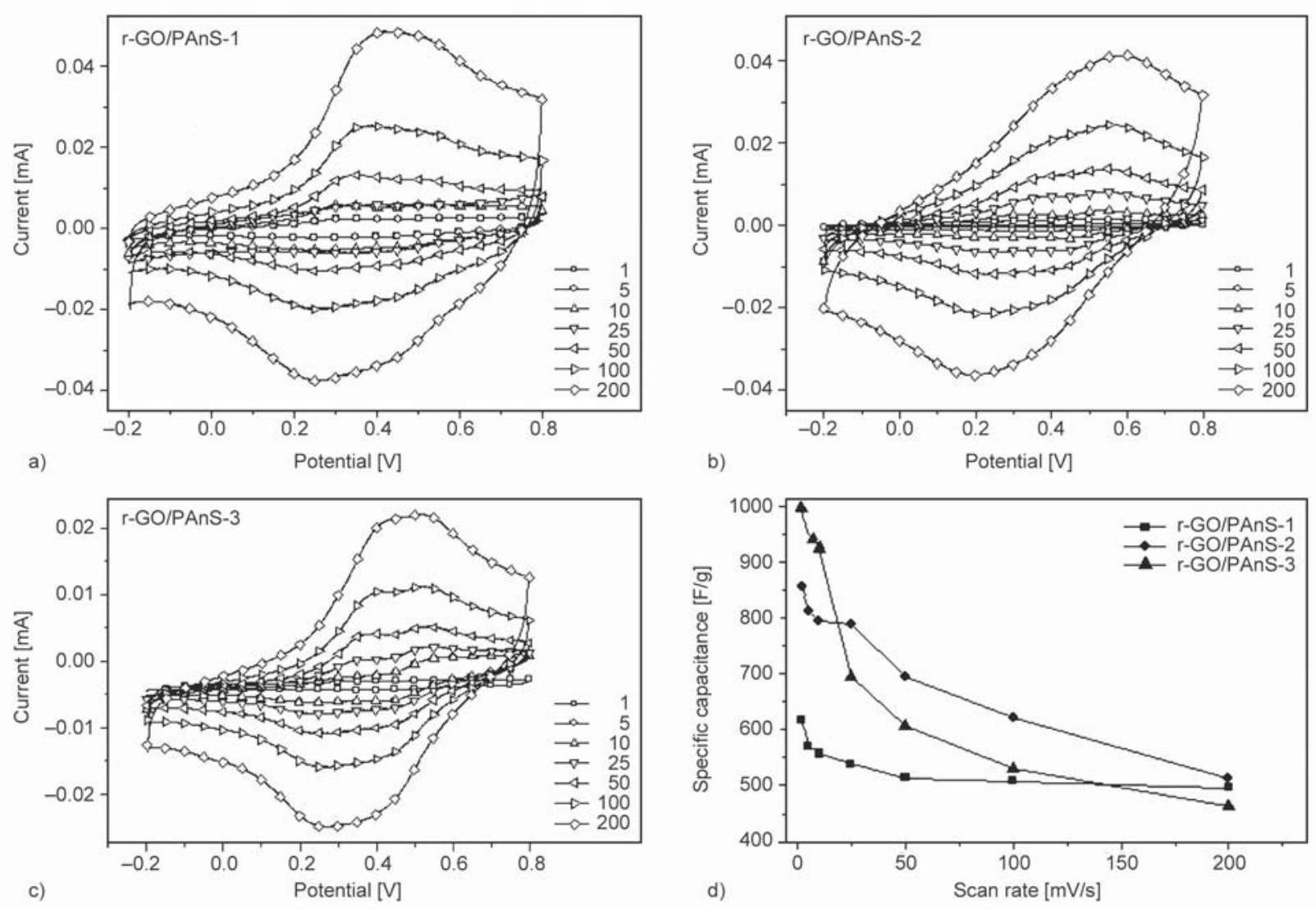

Figure 7. CV curves of a) r-GO/PAnS-1, b) r-GO/PAnS-2, c) r-GO/PAnS-3, at different scan rates (1, 5, 10, 25, 50, 100 and $200 \mathrm{mV} / \mathrm{s}$ ) in $1 \mathrm{M} \mathrm{H}_{2} \mathrm{SO}_{4}$, d) specific capacitance values of r-GO/PAnS-1, r-GO/PAnS-2, r-GO/PAnS-3 as a function of scan rate

good rate properties. Another proof, for good rate ability of these materials is the increasing of current with the scan rates, as can be seen in Figure 7.

It is commonly accepted that the electrochemical capacitance is proportional to the area under $\mathrm{CV}$ curve. Thus, the specific capacitance of the composite film deposited onto glassy carbon electrode can be calculated according the Equation (1) [29]:

$C_{\mathrm{CV}}=\frac{\int I \mathrm{dV}}{V m V}$

where $C_{\mathrm{CV}}$ is the specific capacitance based on the mass of electroactive materials $[\mathrm{F} / \mathrm{g}], I$ is the response current density [A], $V$ is the potential [V], $v$ is the potential scan rate $[\mathrm{mV} / \mathrm{s}]$ and $m$ is the mass of the electroactive materials deposited on the electrode $[\mathrm{g}]$.

The specific capacitance values change with the scan rate, as shown in Figure 7d and higher specific capacitance was observed at low scan rate. As the scan rate has increased, the specific capacitance has decreased, which may be explained by the increase of ions concentration at the electrode/electrolyte interface while the diffusion rate of electrolyte from electrolyte/ electrode interface remain limited to assure electrochemical reactions [45]. Moreover, the increasing the PAnS content in the composites (from $\sim 30 \%$ to $\sim 100 \%$ ) is accompanied by increasing of the specific capacitance due to PAnS faradaic capacitance. In particular, the r-GO/PAnS-3 composite exhibits the highest specific capacitance $(1019 \mathrm{~F} / \mathrm{g})$ at $1 \mathrm{mV} / \mathrm{s}$. The good capacitance can be ascribed to the adequate combination of PAnS with large pseudocapacitance and r-GO with high surface area. Perhaps, for this composition the r-GO sheets are completely covered by the PAnS leading to higher surface area of the composites and faster ion diffusion rate.

Another important property of an electroactive material in supercapacitors is the charge-discharge behavior investigated for the three composites by galvanostatic charge-discharge technique at a current of $1 \mathrm{~mA}$ (Figure 8). For all three composites the chargedischarge curves have similar shapes and are deviated from linear characteristics and this behavior reveals that the capacitance involves electric double layer capacitance (EDLC) that is specific to reduced graphene and Faradic capacitance from sulfonated 


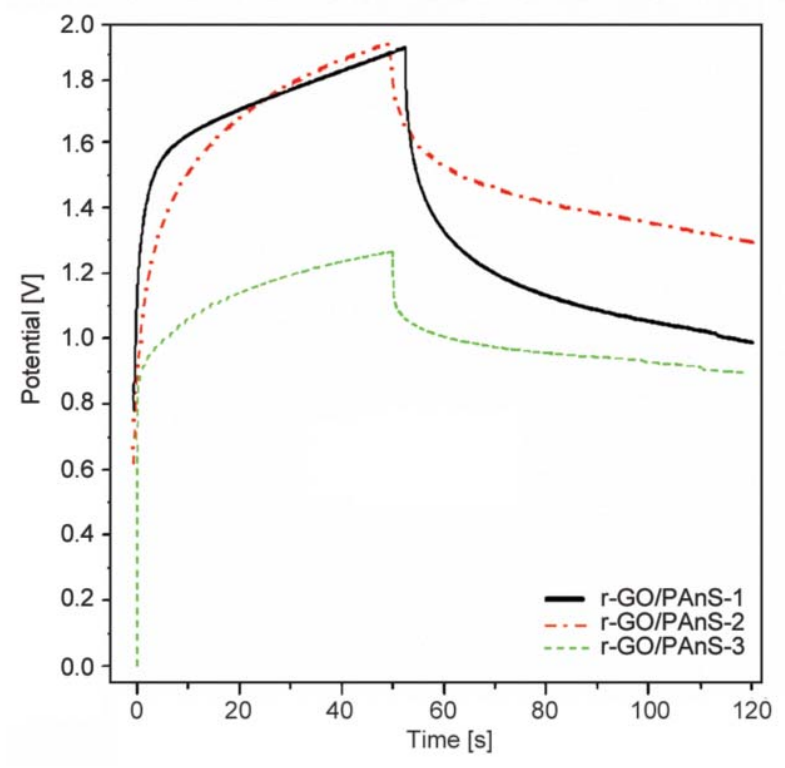

Figure 8. Charge-discharge curves of r-GO/PAnS-1, r-GO/ PAnS-2, r-GO/PAnS-3 at a current of $1 \mathrm{~mA}$

polyaniline. The specific capacitance of composites was estimated on the basis of galvanostatic charge discharge curves using Equation (2):

$C_{\mathrm{CD}}=\frac{I \cdot \Delta t}{m \cdot \Delta V}$

where $C_{\mathrm{CD}}$ is the specific capacitance of the active material $[\mathrm{F} / \mathrm{g}], I$ is the discharge current $[\mathrm{A}], \Delta t$ is the discharge time [s], $m$ is the mass of the sample [g], $\Delta V$ is the potential range [V] [22]. The calculated specific capacitance of composites has values of $420 \mathrm{~F} / \mathrm{g}$ for $\mathrm{r}-\mathrm{GO} / \mathrm{PAnS}-1,541 \mathrm{~F} / \mathrm{g}$ for $\mathrm{r}-\mathrm{GO} / \mathrm{PAnS}-2$ and $812 \mathrm{~F} / \mathrm{g}$ for $\mathrm{r}-\mathrm{GO} / \mathrm{PAnS}-3$, respectively. These values are lower than the results given for cyclic voltammetry measurements.

The electrochemical stability of the composites was tested in $1 \mathrm{M} \mathrm{H}_{2} \mathrm{SO}_{4}$ aqueous as electrolyte by consecutive charge-discharge cycles at current density of

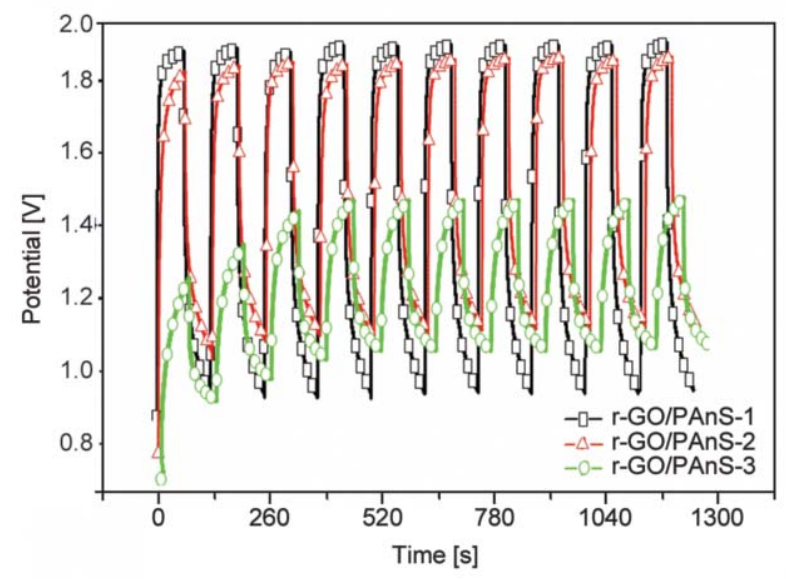

Figure 9. Charge-discharge curves for $\mathrm{r}-\mathrm{GO} / \mathrm{PAnS}-1, \mathrm{r}-\mathrm{GO} /$ PAnS-2, r-GO/PAnS-3, after 10 cycles
$1 \mathrm{~mA}$. As shown in Figure 9, the composites r-GO/ PAnS-1 and r-GO/PAnS-2 present good cyclic stability and this explanation is sustained with almost symmetric charge-discharge curves. In case of $\mathrm{r}-\mathrm{GO} /$ PAnS-3, the galvanostatic charge-discharge plots showed small deviation to cyclic stability and this result is due to the higher content of PAnS in composite. It is known that polyaniline materials show low dimensional stability in the electrochemical processes due to poor mechanical properties, repetitive swelling and shrinkage of the film and irreversible degradation of PAnS during the oxidation and reduction processes. The introduction of r-GO into composites enhances mechanical properties and provides relatively high areas for template polymerization of AnS. However, with increasing the AnS content the surface of r-GO is not sufficient as a template and a thick film of PAnS coated r-GO. During the electrochemical studies PAnS can be partially freed from the surface of the electrode in the electrolyte contributing also to the deterioration of capacitance and cycle life.

The stability of composites was evaluated using constant current cycling over 100 continuous charge-discharge cycles. A typical life cycle of r-GO/PAnS-3 is shown in Figure 10. As can be seen the initial specific capacitance is high and it rapidly decreases for the 100 cycles and then remain constant. The retention life of $80 \%$ was calculated after 100 cycles.

\section{Conclusions}

In summary, we have successfully synthesized freesurfactant water dispersions of reduced graphene oxide/poly(aniline- $N$-propane sulfonic acid) composites by chemical oxidative polymerization of aniline- $N$-propane sulfonic acid in r-GO dispersion. The

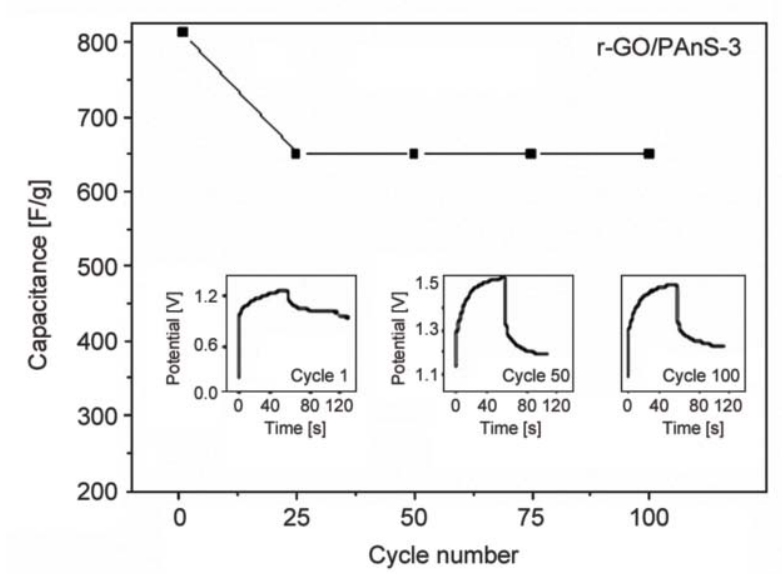

Figure 10. Life cycle of r-GO/PAnS-3 at a current of $1 \mathrm{~mA}$ 
composites structure was proved by different spectral techniques such as FTIR, ultraviolet-visible and Raman spectroscopy, X-ray diffraction and scanning electron microscopy. Cyclic voltammetry and galvanostatic charge-discharge techniques were used for electrochemical studies and showed that the synthesized composites possessed high electrochemical capacitance and good to moderate stability. The composite r-GO/PAnS-3 has showed good capacitive behavior with a specific capacitance of $1019 \mathrm{~F} / \mathrm{g}$ at scan rate of $1 \mathrm{mV} / \mathrm{s}$ and a retention life of $80 \%$ after 100 cycles. The enhanced specific capacitance of the $\mathrm{r}-\mathrm{GO} / \mathrm{PAnS}$ composites is due to the synergistic effect of the r-GO and PAnS.

\section{Acknowledgements}

The authors thank to the Romanian National Authority for Scientific Research (UEFISCDI) for financial support (Grant PN-II-ID-PCE-2011-3-0274, Contract 148/2011).

\section{References}

[1] Conway B. E.: Electrochemical supercapacitors: Scientific fundamentals and technological applications. Kluwer, New York (1999).

[2] Stoller M. D., Park S., Zhu Y., An J., Ruoff R. S.: Graphene-based ultracapacitors. Nanoletters, 8, 3498 3502 (2008). https://doi.org/10.1021/nl802558y

[3] Raccichini R., Varzi A., Passerini S., Scrosati B.: The role of graphene for electrochemical energy storage. Nature Materials, 14, 271-279 (2015). https://doi.org/10.1038/NMAT4170

[4] Novoselov K. S., Geim A. K., Morozov S. V., Jiang D., Zhang Y., Dubonos S. V., Grigorieva I. V., Firsov A. A.: Electric field effect in atomically thin carbon films. Science, 306, 666-669 (2004). https://doi.org/10.1126/science.1102896

[5] Geim A. K., Novoselov K. S.: The rise of graphene. Nature Materials, 6, 183-191 (2007).

https://doi.org/10.1038/nmat1849

[6] Ivanovskii A. L.: Graphene-based and graphene-like materials. Russian Chemical Reviews, 81, 571-605 (2012). https://doi.org/10.1070/RC2012v081n07ABEH004302

[7] Chen J., Li C., Shi G.: Graphene materials for electrochemical capacitors. Journal of Physical Chemistry Letters, 4, 1244-1253 (2013). https://doi.org/10.1021/jz400160k

[8] Chen K., Song S., Liu F., Xue D.: Structural design of graphene for use in electrochemical energy storage devices. Chemical Society Reviews, 44, 6230-6257 (2015). https://doi.org/10.1039/C5CS00147A
[9] Pud A., Ogurtsov N., Korzhenko A., Shapoval G.: Some aspects of preparation methods and properties of polyaniline blends and composites with organic polymers. Progress in Polymer Science, 28, 1701-1753 (2003). https://doi.org/10.1016/j.progpolymsci.2003.08.001

[10] Anand J., Palaniappan S. A., Sathyanarayana D. N.: Conducting polyaniline blends and composites. Progress in Polymer Science, 23, 993-1018 (1998). https://doi.org/10.1016/S0079-6700(97)00040-3

[11] Ćirić-Marjanović G.: Recent advances in polyaniline research: Polymerization mechanisms, structural aspects, properties and applications. Synthetic Metals, 177, 1-47 (2013).

https://doi.org/10.1016/j.synthmet.2013.06.004

[12] Wei X-L., Wang Y. Z., Long S. M., Bobeczko C., Epstein A. J.: Synthesis and physical properties of highly sulfonated polyaniline. Journal of American Chemical Society, 118, 2545-2555 (1996).

https://doi.org/10.1021/ja952277i

[13] Kuilla T., Bhadra S., Yao D. H., Kim N. H., Bose S., Lee J. H.: Recent advances in graphene based polymer composites. Progress in Polymer Science, 35, 13501375 (2010). https://doi.org/10.1016/j.progpolymsci.2010.07.005

[14] Kim H., Abdala A., Macosko C.: Graphene/polymer nanocomposites. Macromolecules, 43, 6515-6530 (2010). https://doi.org/10.1021/ma100572e

[15] Potts J. R., Dreyer D. R., Bielawski C. W., Ruoff R. S.: Graphene-based polymer nanocomposites. Polymer, 52, 5-25 (2011). https://doi.org/10.1016/j.polymer.2010.11.042

[16] Huang Y., Liang J., Chen Y.: An overview of the applications of graphene-based materials in supercapacitors. Small, 8, 1805-1834 (2012). https://doi.org/10.1002/smll.201102635

[17] Xu Y., Luo J., Yao W., Xu J., Li T.: Preparation of reduced graphene oxide/flake carbonyl iron powders/polyaniline composites and their enhanced microwave absorption properties. Journal of Alloys and Compounds, 636, 310-316 (2015). https://doi.org/10.1016/j.jallcom.2015.02.196

[18] Chang C-H., Huang T-C., Peng C-W., Yeh T-C., Lu HI., Hung W-I., Weng C-J., Yang T-I., Yeh J-M.: Novel anticorrosion coatings prepared from polyaniline/ graphene composites. Carbon, 50, 5044-5051 (2012). https://doi.org/10.1016/j.carbon.2012.06.043

[19] Wan L., Wang B., Wang S., Wang X., Cuo Z., Xiong H., Dong B., Zhao L., Lu H., Xu Z., Zhang X., Li T., Zhou T.: Water-soluble polyaniline/graphene prepared by in situ polymerization in graphene dispersions and use as counter-electrode materials for dye-sensitized solar cells. Reactive and Functional Polymers, 79, 4753 (2014).

https://doi.org/10.1016/j.reactfunctpolym.2014.03.012 
[20] Wang H., Hao Q., Yang X., Lu L., Wang W.: A nanostructured graphene/polyaniline hybrid material for supercapacitors. Nanoscale, 2, 2164-2170 (2010). https://doi.org/10.1039/c0nr00224k

[21] Zhang K., Zhang L. L., Zhao X. S., Wu J.: Graphene/ polyaniline nanofiber composites as supercapacitor electrodes. Chemistry of Materials, 22, 1392-1401 (2010). https://doi.org/10.1021/cm902876u

[22] Wang D-W., Li F., Zhao J., Ren W., Chen Z-G., Tan J., Wu Z-S., Gentle I., Ga Q. L., Cheng H-M.: Fabrication of graphene/polyaniline composite paper via in situ anodic electropolymerization for high-performance flexible electrode. ACS Nano, 3, 1745-1752 (2009).

https://doi.org/10.1021/nn900297m

[23] Goswami S., Maiti U. N., Maiti S., Nandy S., Mitra M. K., Chattopadhyay K. K.: Preparation of graphene-polyaniline composites by simple chemical procedure and its improved field emission properties. Carbon, 49, 2245-2252 (2011). https://doi.org/10.1016/j.carbon.2011.01.055

[24] Vega-Rios A., Rentería-Baltiérrez F. Y., Hernández-Escobar C. A., Zaragoza-Contreras E. A.: A new route toward graphene nanosheet/polyaniline composites using a reactive surfactant as polyaniline precursor. Synthetic Metals, 184, 52-60 (2013).

https://doi.org/10.1016/j.synthmet.2013.09.014

[25] Coşkun E., Zaragoza-Contreras E. A., Salavagione H. J.: Synthesis of sulfonated graphene/polyaniline composites with improved electroactivity. Carbon, 50, 22352243 (2012).

https://doi.org/10.1016/j.carbon.2012.01.041

[26] Li G., Li Y., Peng H., Qin Y.: Synthesis and electrochemical performances of dispersible polyaniline/sulfonated graphene composite nanosheets. Synthetic Metals, 184, 10-15 (2013).

https://doi.org/10.1016/j.synthmet.2013.09.016

[27] Tan F., Tong S., Zeng W., Niu Q., Liu Y., Kao C-Y.. Liu J., Huang W., Min Y., Epstein A. J.: Self-assembling sulfonated graphene/polyaniline nanocomposite paper for high performance supercapacitor. Synthetic Metals, 199, 79-86 (2015). https://doi.org/10.1016/j.synthmet.2014.11.017

[28] Ma B., Zhou X., Bao H., Li X., Wang G.: Hierarchical composites of sulfonated graphene-supported vertically aligned polyaniline nanorods for high-performance supercapacitors. Journal of Power Sources, 215, 36-42 (2012).

https://doi.org/10.1016/j.jpowsour.2012.04.083

[29] Jin Y., Huang S., Zhang M., Jia M.: Preparation of sulfonated graphene-polyaniline nanofiber composites by oil/water interfacial polymerization and their application for supercapacitors. Synthetic Metals, 168, 58-64 (2013).

https://doi.org/10.1016/j.synthmet.2013.02.007
[30] Wang G., Tang Q., Bao H., Li X., Wang G.: Synthesis of hierarchical sulfonated graphene $/ \mathrm{MnO}_{2} /$ polyaniline ternary composite and its improved electrochemical performance. Journal of Power Sources, 241, 231-238 (2013).

https://doi.org/10.1016/j.jpowsour.2013.04.122

[31] Jung J. W., Lee J. U., Jo W. H.: High-efficiency polymer solar cells with water-soluble and self-doped conducting polyaniline graft copolymer as hole transport layer. The Journal of Physical Chemistry C, 114, 633639 (2010). https://doi.org/10.1021/jp9083844

[32] Bae W. J., Kim K. H., Park Y. H., Jo W. H.: A novel water-soluble and self-doped conducting polyaniline graft copolymer. Chemical Communications, 22, 27682769 (2003). https://doi.org/10.1039/B309346H

[33] Liu X., Shang P., Zhang Y., Wang X., Fan Z., Wang B., Zheng Y.: Three-dimensional and stable polyanilinegrafted graphene hybrid materials for supercapacitor electrodes. Journal of Materials Chemistry A, 2, 1527315278, (2014). https://doi.org/10.1039/C4TA03077J

[34] Gao Z., Wang F., Chang J., Wu D., Wang X., Wang X., Xu F., Gao S., Jiang K.: Chemically grafted graphenepolyaniline composite for application in supercapacitor. Electrochimica Acta, 133, 325-334 (2014). https://doi.org/10.1016/j.electacta.2014.04.033

[35] Liu J., An J., Zhou Y., Ma Y., Li M., Yu M., Li S.: Preparation of an amide group-connected graphene-polyaniline nanofiber hybrid and its application in supercapacitors. ACS Applied Materials \& Interfaces, 4, 2870 2876 (2012). https://doi.org/10.1021/am300640y

[36] Song B., Tuan C-C., Huang X., Li L., Moon K-S., Wonh C-P.: Sulfonated polyaniline decorated graphene nanocomposites as supercapacitor electrodes. Materials Letters, 166, 12-15 (2016). https://doi.org/10.1016/j.matlet.2015.11.108

[37] Bai H., Xu Y., Zhao L., Li C., Shi G.: Non-covalent functionalization of graphene sheets by sulfonated polyaniline. Chemical Communications, 2009, 1667-1669 (2009). https://doi.org/10.1039/b821805f

[38] Hummers W. S., Offeman R. E.: Preparation of graphitic oxide. Journal of American Chemical Society, 80, 1339 (1958).

https://doi.org/10.1021/ja01539a017

[39] Grigoras M., Catargiu A. M., Tudorache F., Dobromir M.: Chemical synthesis and characterization of selfdoped $N$-propanesulfonic acid polyaniline derivatives. Iranian Polymer Journal, 21, 131-141 (2012). https://doi.org/10.1007/s13726-011-0011-0 
[40] Eckmann A., Felten A., Verzhbitskiy I., Davey R., Casiraghi C.: Raman study on defective graphene: Effect of the excitation energy, type, and amount of defects. Physical Review B, 88, 035426/1-035426/11 (2013). https://doi.org/10.1103/PhysRevB.88.035426

[41] Tuinstra F., Koenig J. L.: Raman spectrum of graphite. Journal of Chemical Physics, 53, 1126-1130 (1970). https://doi.org/10.1063/1.1674108

[42] Malard L. M., Pimenta M. A., Dresselhaus G., Dresselhaus M. S.: Raman spectroscopy in graphene. Physics Reports, 473, 51-87 (2009).

https://doi.org/10.1016/j.physrep.2009.02.003
[43] Stankovich S., Dikin D. A., Piner R. D., Kohlhaas K. A., Kleinhammes A., Jia Y., Wu Y., Nguyen S. T., Ruoff R. S.: Synthesis of graphene-based nanosheets via chemical reduction of exfoliated graphite oxide. Carbon, 45, 1558-1565 (2007). https://doi.org/10.1016/j.carbon.2007.02.034

[44] Kim E. K., Lee M. S., Lee M-H., Rhee S. B.: Liquid crystalline assemblies from self-doped polyanilines. Synthetic Metals, 69, 101-104 (1995). https://doi.org/10.1016/0379-6779(94)02377-B

[45] Mujawar S. H., Ambade S. B., Battumur T., Ambade R. B., Lee S-H.: Electropolymerization of polyaniline on titanium oxide nanotubes for supercapacitor application. Electrochimica Acta, 56, 4462-4466 (2011). https://doi.org/10.1016/j.electacta.2011.02.043 